\title{
Chamber stapes prosthesis with an improved fastening of the membrane
}

\author{
Małgorzata Pudlik ${ }^{1, *}$, Henryk Skarżyński ${ }^{2}$, and Monika Kwacz ${ }^{3}$ \\ ${ }^{1}$ Institute of Radioelectronics, Warsaw University of Technology, Nowowiejska 15/17, 00-665 Warsaw, Poland \\ ${ }^{2}$ Institute of Physiology and Pathology of Hearing, Mochnackiego 10, 02-042 Warsaw, Poland \\ ${ }^{3}$ Institute of Micromechanics and Photonics, Warsaw University of Technology, św. Andrzeja Boboli 8, 02-525 Warsaw, Poland
}

\begin{abstract}
Stapes prostheses are dedicated to assisting patients with otosclerosis. Currently used stapes prostheses have the form of a piston and are called piston prostheses. However, the perilymph excitation by piston prosthesis is not perfect so a new chamber stapes prosthesis (ChSP) has been proposed. The ChSP allows for a more effective stimulation of the cochlea than the piston. A crucial element of the ChSP is a flexible membrane. The membrane transmits vibrations from the plate to the fluid that fills the chamber and then to the inner ear. In the first prototype, the membrane was glued to the chamber, which is an unacceptable solution in a real medical device because of a risk to patient's health. Therefore, there is a need to improve the membrane fastening. In this study, we present a new improved method for attaching the membrane to the chamber. A modified 3D model of the ChSP was build and an additional fastening element was designed. The design process of the fastening element was based on the analysis of deformation conducted for elements made of different materials. As a result the optimal geometry of the element was determined. The new fastening has been experimentally tested using the 3D printed model. Fastening the membrane to the prosthesis was a success and assessed as efficient. The results of the experimental tests confirmed that presented modification can be used in the ChSPs intended for clinical trials.
\end{abstract}

\section{Introduction}

As acoustic waves enter the human auditory system, they are transmitted through its consecutive parts: the outer ear, the middle ear, and the inner ear. In one of these, the middle ear, three ossicles: malleus, incus and stapes are located. The last one, stapes, is the smallest bone in the human body. The footplate of the stapes is attached to the oval window (OW) niche and transmits the vibrations thereof, stimulating the fluid (perilymph) which fills the cochlea (the inner ear). The middle ear is thus responsible for providing efficient transfer of sound from the air to the inner ear, which results in the excitation of the basilar membrane vibrations. Mechanical waves from the cochlea are finally converted to electric signals in neurones, which constitutes the hearing process, given that the auditory system functions properly. In certain cases pathologies may lead to hearing loss as a result of e.g. a disease called stapes otosclerosis. In otosclerosis, the mobility of the stapes is reduced or stopped completely. This is caused by non natural bone remodelling in the OW niche $[1,2]$.

There are many factors contributing to otosclerosis, hence standard treatment cannot be applied. According to the scientific literature, the most effective treatment for otosclerosis is a surgical procedure [3-5]. The first otic surgery called stapedectomy was performed by Shea in 1956, by replacing the stapes with a prosthesis and covering the OW with a living membrane [6]. A modified operation, stapedotomy, is currently the most common technique for reconstructing the sound conducting mechanism of the middle ear and reducing hearing loss. During stapedotomy, a stapedial suprastructure is removed and then a small hole $(0.4-0.7 \mathrm{~mm})$ in the stapes footplate is made. Then a prosthesis is attached on one side to the long process of the incus and on the other the piston is inserted to the newly created hole. Currently used stapes prostheses, typically come in the form of a piston. They are called piston prostheses; an example of one of those is presented in Fig.1 A.

For many years, scientists have conducted research concerning improvement of the stapes surgery performance. This research has resulted in the development of various types of piston prostheses. Currently used piston prostheses differ in the type of material (e.g. Teflon, titanium, gold), the piston diameter, or the attachment method to the incus [8-10]. However, only few researchers focus on improving efficacy, especially for frequencies above $2 \mathrm{kHz}$, which is the main problem with piston prosthesis. Therefore, in 2014, a new type of prosthesis was proposed [11]. It is called the chamber stapes prosthesis (ChSP) and its design is shown in Fig.1B.

\footnotetext{
* Corresponding author: mgpudlik@gmail.com
} 


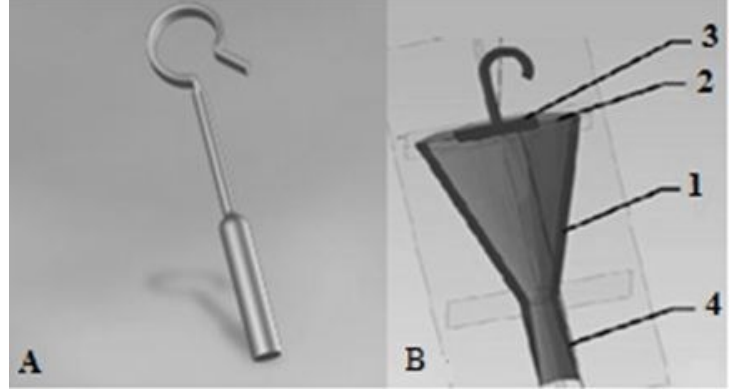

Fig.1. (A) Typical piston prosthesis [7]. (B) Design of chamber stapes prosthesis (ChSP) [12]. 1 - chamber filled with fluid, 2 -flexible membrane, 3 - plate with an attachment, 4 - capillary tube.

Computer simulations, carried out to preliminarily verify the functioning of the ChSP, have shown ChSP superiority compared to the standard piston prosthesis [12]. The tests consisted in studying the vibrations of the basilar membrane (BM) induced by the prostheses compared with the $\mathrm{BM}$ vibration in the physiological ear model. The results of the numerical simulation showed that the ChSP provides better excitement of the BM than the piston prosthesis and similar or slightly better than the physiological stapes footplate. The findings of the study suggested that the clinical use of the ChSP could give better postoperative hearing results compared with the standard piston prosthesis.

Then the experimental preclinical studies were conducted by measuring vibrations of the round window (RW) membrane in the human temporal bone before and after implantation of the ChSP prototype, using a scanning laser-Doppler vibrometer [13]. The measurement results confirmed the superiority of the ChSP over the piston prosthesis, especially for frequencies above $2 \mathrm{kHz}$.

The key element in the design of the ChSP is a flexible membrane ( 2 in Fig.1B). The membrane allows the vibration to be transmitted from the plate to the fluid filling the chamber. Except that, the membrane should ensure tight closure of the chamber. During the first experiments, the membrane, which was glued to the chamber, sometimes peeled off of the prosthesis. This is unacceptable in a real medical prosthesis because of a risk to patient's health. The loss of tightness of the chamber and resulting fluid outflow poses a risk of infection in the inner ear, which can lead to inflammation and, in the worst case, to a hearing loss. Therefore, there is a need to improve the fastening of the membrane.

\subsection{Objective}

The objective of this study is to find, determine and test the best solution for the detected problem associated with bonding the membrane to the chamber and holding it in the desired place in the prosthesis. To this end, (i) a conceptual design of a new membrane fastening should be created, (ii) a 3D-CAD model of the chamber should be modified, (iii) a new fastening element should be designed, (iv) the ChSP with the new membrane fastening should be manufactured and tested experimentally.

\section{Methods}

\subsection{Conceptual design}

The conceptual design (Fig.2) for an improved fastening of the membrane consists in creating a groove (2) in the prosthesis chamber (1) and subsequently placing an additional fastening element (3) in this groove. The additional element, resembling a ring, was designed to keep the membrane (4) and is applied on the open upper surface of the chamber.

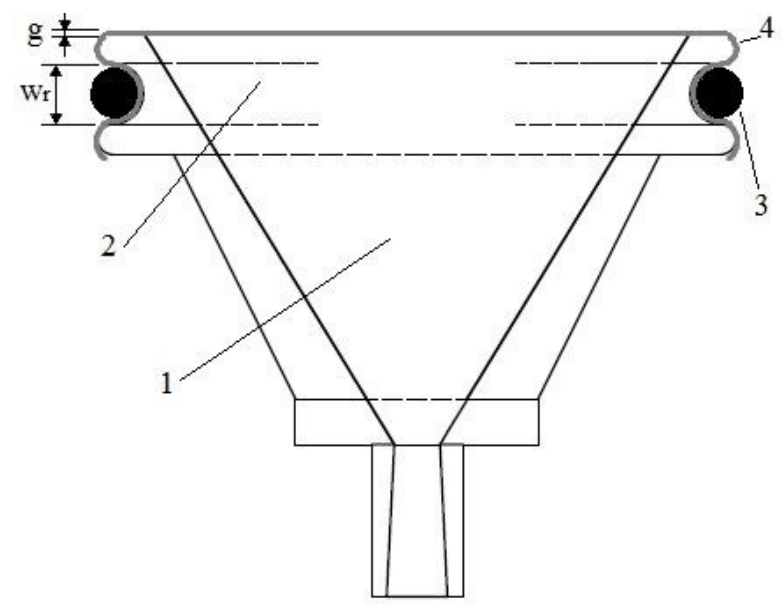

Fig. 2. Conceptual design for an improved fastening of the membrane. 1 - chamber, 2 - groove with height $\mathrm{w}_{\mathrm{r}}$, 3 - additional fastening element, 4 - membrane with thickness g.

\subsection{D-CAD model and 3D print of the chamber}

A modified 3D model (Fig.3A) of the chamber geometry was built using Autodesk Inventor 2015. The model was created according to the technical documentation according to all the design, technological and functional requirements, e. $g$. rounded edges that prevent damage to the membrane, and dimensions that ensure proper implantation of the ChSP in the middle ear. The 3D-CAD model was saved in the STL format.

The complete STL model of the chamber was checked using Autodesk Netfabb 2017. This software delivers all of the necessary tools to fix the geometry and prepare files for 3D printing.

To manufacture the modified ChSP, one of the additive manufacturing technologies, MJP (Multi Jet Printing), was. The MJP method allows printing complex geometries with high accuracy, even up to 16 microns. This feature is critical to manufacturing such small elements like a stapes prosthesis. The 3D model of the chamber was printed (Fig.3B) by I.J. Paliga (www.ijpaliga.pl) using a PolyJet3500 machine. The printer specifications and properties of the building material are collected in Table 1. 
Table 1. Printer specifications and properties of the material used in the manufacturing process of the modified ChSP.

\begin{tabular}{|c|c|}
\hline $\begin{array}{c}\text { Accuracy } \\
\text { of 3D } \\
\text { printing }\end{array}$ & $\begin{array}{c}\text { layer thickness }-16 \mu \mathrm{m} ; \\
\text { resolution }-750 \times 750 \mathrm{DPI}\end{array}$ \\
\hline $\begin{array}{c}\text { Work } \\
\text { space }\end{array}$ & $289 \times 185 \times 203 \mathrm{~mm}$ \\
\hline Wares & $\begin{array}{c}\text { minimum wall thickness }-0.2 \mathrm{~mm} \text {; smooth } \\
\text { surface, moving parts, functional and thin- } \\
\text { walled models }\end{array}$ \\
\hline
\end{tabular}

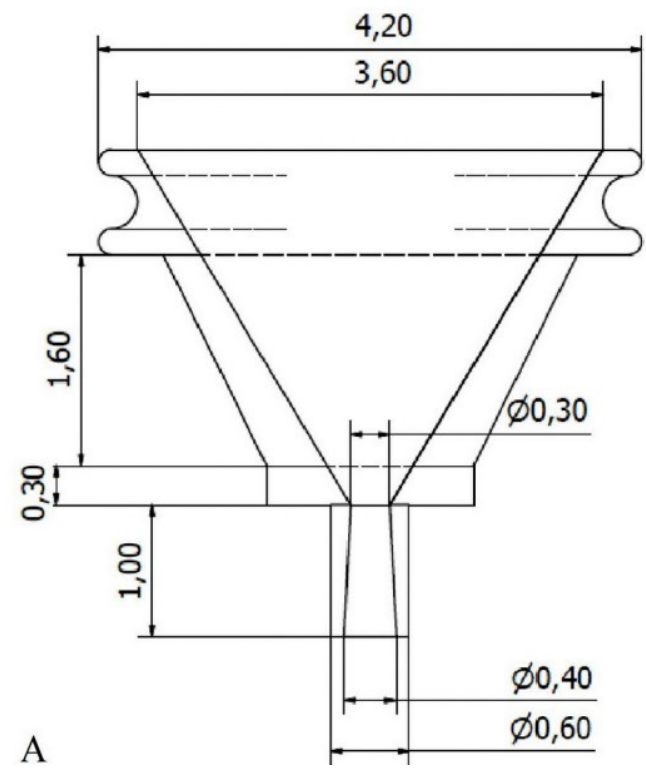

\begin{tabular}{|c|c|}
\hline \multirow{4}{*}{ Material } & photopolymer (VisiJet $\mathrm{M} 3 \mathrm{X}$ ) with properties: \\
density $-1,1 \mathrm{~g} / \mathrm{cm}^{3} ;$ \\
tensile strength $-49 \mathrm{MPa} ;$ \\
bending strength $-65 \mathrm{MPa} ;$ \\
modulus of elasticity $\mathrm{E}-2168 \mathrm{MPa}$; heat \\
resistance $-88^{\circ} \mathrm{C}$
\end{tabular}

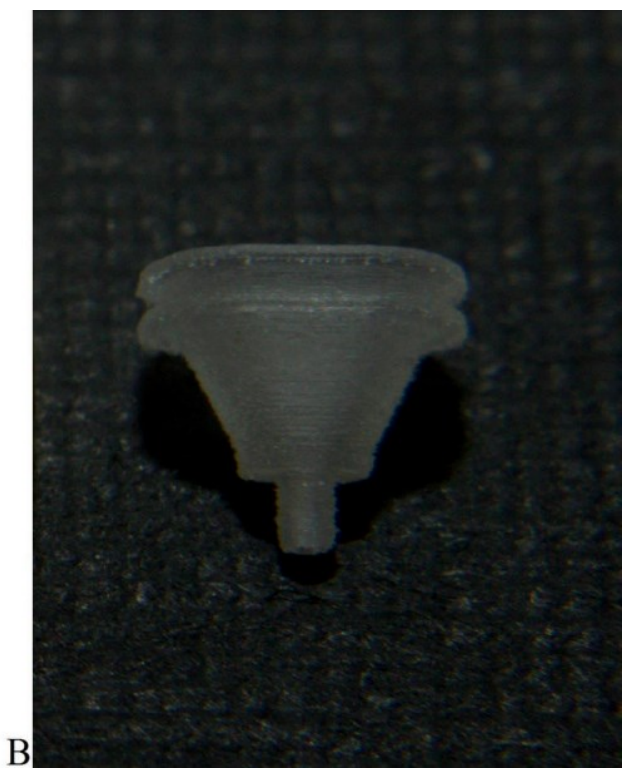

Fig. 3. Modified model of the chamber. (A) Front projection of model built using Autodesk Inventor 2015 (dimensions in mm). (B) 3D printed model.

\subsection{Design of the fastening element}

The fastening element in the shape of a ring was designed in two variants (Fig. 4): (1) an o-ring with a circular cross-section, and (2) a ring with a rectangular cross-section (a very short section of a thin-walled tube).

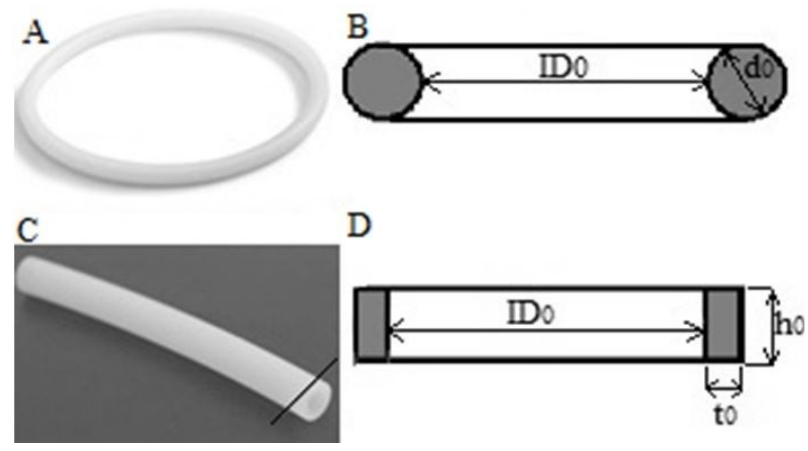

Fig. 4. Two variants of fastening elements. (A) a commercial o-ring (www.alliedmetrics.com). (B) the cross-section of the oring with $I D_{0}$ and $d_{0}$ dimensions. (C) a commercial thin-walled tube with marked cut-off location (www.printo3d.pl, selfmodified), (D) the cross-section of the ring after cut off from the tube with $I D_{0}, t_{0}$ and $h_{0}$ dimensions.
Each of the rings was designed to be made from the following two materials that have a wide range of applications in medicine: (1) PTFE (polytetrafluoroethylene) and (2) PDMS (polydimethylsiloxane), the latter being a polymer from the group of siloxanes. Both these materials are biocompatible and non-toxic. During the designing stage the material properties such as the range of elasticity $(\varepsilon)$, Poisson's ratio $(v)$ and Young's modulus (E) were taken into account (see Table 2). Stresses in the material, both during the application of the ring and during the whole period of use of the prosthesis should not exceed the elastic limit of the material. Moreover, it was necessary to adjust the ring dimensions to fit into the groove (see Fig.2).

Table 2. Material properties of PTFE and PDMS (data from: $1-[14], 2-[15], 3-[16], 4-[17])$.

\begin{tabular}{|l|c|c|c|}
\hline & $\begin{array}{c}\text { Range of } \\
\text { elasticity at } \\
\text { ambient } \\
\text { temperature, } \\
\boldsymbol{\varepsilon}(\%)\end{array}$ & $\begin{array}{c}\text { Poisson's } \\
\text { ratio, } \\
\mathbf{v}(-)\end{array}$ & $\begin{array}{c}\text { Young's } \\
\text { modulus, } \\
\text { E (MPa) }\end{array}$ \\
\hline PTFE & $10^{1)}$ & $0,46^{3)}$ & $20^{1)}$ \\
\hline PDMS & $50^{2)}$ & $0,5^{4}$ & $1,3^{4)}$ \\
\hline
\end{tabular}




\subsubsection{Round cross-section ring (o-ring)}

For the round cross-section ring, the dimensions necessary to determine were: (1) the cross-sectional diameter $\left(d_{0}\right)$, and (2) the inner diameter $\left(I D_{0}\right)$ for the unstretched ring (Fig.4B).

Taking into account the thickness of the membrane in the groove (see Fig. 2), the cross-sectional diameter $\left(d_{1}\right)$ after stretching was:

$$
d_{1}=w_{r}-2 g
$$

where:

$w_{r}$ - height of the groove (in this study $w_{r}=0.4 \mathrm{~mm}$ ),

$g$ - thickness of the membrane (in $\mathrm{mm}$ ).

When calculating the cross-sectional diameter $\left(d_{0}\right)$ of the ring before stretching, the relationship (2) between the transverse and longitudinal strains under the stretching force was used.

The manner in which the material deforms is determined by the dimensionless Poisson's ratio $(v) ; v$ is defined, as the ratio of the transverse strain to the longitudinal strain :

$$
v=-\frac{\varepsilon_{p}}{\varepsilon_{w}}
$$

where:

$\varepsilon_{p}-$ transverse strain (\%),

$\varepsilon_{w}-$ longitudinal strain (\%).

In our modified ChSP, the longitudinal strain $\left(\varepsilon_{w}\right)$ is defined as an increase in the ring circumference after stretching relative to the ring circumference before stretching:

$$
\varepsilon_{w}=\frac{L_{1}-L_{0}}{L_{0}} \cdot 100 \%
$$

where,

$L_{0}$ - circumference of the ring before stretching (in $\mathrm{mm}$ ), $L_{1}$-circumference of the ring after stretching (in $\mathrm{mm}$ ).

Similarly, the transverse strain $\left(\varepsilon_{p}\right)$ of the round cross-section ring is defined as:

$$
\varepsilon_{p}=\frac{d_{1}-d_{0}}{d_{0}} \cdot 100 \%
$$

where,

$d_{0}-$ cross-sectional diameter of the ring before stretching (in $\mathrm{mm}$ ),

$d_{1}-$ cross-sectional diameter of the ring after stretching (in $\mathrm{mm}$ ).

Converting the equation (4) and using the relationship (2), the cross-sectional diameter $\left(d_{0}\right)$ for the unstretched ring is:

$$
d_{0}=\frac{d_{1}}{1-v \cdot \frac{\varepsilon_{p}}{100}}
$$

Taking into account (1) and $v$ and $\varepsilon$ values given in Table 2 , the $d_{0}$ values were calculated from (5). The resulting $d_{0}$ values for different membrane thickness $(g)$ are listed in Table 3.

To calculate $I D_{0}$, the circumference $\left(L_{1}\right)$ of the groove that incorporates the membrane of thickness $(\mathrm{g})$ was determined for different values of the g. Next, the $L_{0}$ values for rings before stretching and finally the $I D_{0}$ values were calculated using (2) and (3). The resulting $I D_{0}$ values for different membrane thickness $(\mathrm{g})$ are listed in Table 3.

Table 3. The cross-sectional diameter $\left(d_{0}\right)$ and the inner diameter $\left(I D_{0}\right)$ of the unstretched o-ring for different thicknesses (g) of the membrane.

\begin{tabular}{|c|c|c|c|c|c|}
\hline \multirow{2}{*}{$\begin{array}{c}\text { membrane } \\
\text { material }\end{array}$} & \multirow{2}{*}{$\begin{array}{c}\mathbf{g} \\
\mathbf{( m m})\end{array}$} & \multicolumn{2}{|c|}{$\boldsymbol{d}_{\mathbf{0}}(\mathbf{m m})$} & \multicolumn{2}{c|}{ ID $_{\mathbf{0}}(\mathbf{m m})$} \\
\cline { 3 - 6 } & & PTFE & PDMS & PTFE & PDMS \\
\hline PTFE & 0.05 & 0.31 & 0.40 & 2.93 & 2.15 \\
\hline PTFE & 0.10 & 0.21 & 0.27 & 3.03 & 2.22 \\
\hline PDMS & 0.10 & 0.21 & 0.27 & 3.03 & 2.22 \\
\hline PDMS & 0.11 & 0.19 & 0.24 & 3.04 & 2.23 \\
\hline PDMS & 0.12 & 0.17 & 0.21 & 3.06 & 2.25 \\
\hline PDMS & 0.13 & 0.15 & 0.19 & 3.08 & 2.26 \\
\hline PDMS & 0.14 & 0.13 & 0.16 & 3.10 & 2.27 \\
\hline PDMS & 0.15 & 0.10 & 0.13 & 3.12 & 2.29 \\
\hline
\end{tabular}

After determining the o-ring dimensions, the catalogues of different companies, both Polish and foreign, i.e. Apple Rubber (www.applerubber.com), the Precision Associates c(www.precisionassoc.com), were browsed to choose the o-rings with the $d_{0}$ and $I D_{0}$ dimensions close to the calculated values (Table 3 ). The chosen o-rings have been verified for the range of elasticity $(10 \%$ for PTFE and 50\% for PDMS, according to Table 2) and filling of the groove (less than $0.4 \mathrm{~mm}$ ). After collecting the best fit of available o-rings, the strain values far exceeded the specified limits of elasticity. Finally, among analyzed rings, the PDMS o-ring with dimensions: $I D_{0}=$ $1.5 \mathrm{~mm}, d_{0}=0.25 \mathrm{~mm}$ (from Apple Rubber) was acceptable, with the greater allowed range of extensibility, i.e. around $120 \%$.

\subsubsection{Rectangular cross-section ring}

For the rectangular cross-section ring (Fig. 4D), the dimensions necessary to determine are : (1) the inner diameter $I D_{0}$, (2) the wall thickness $\left(t_{0}\right)$, and (3) the ring height $\left(h_{0}\right)$ for the unstretched ring. The $h_{0}$ is likewise the length that should be cut of from the tube (Fig. 4C) to make the ring that properly fills the groove.

The $I D_{0}$ values are the same as the values calculated for the inner diameter of the o-ring (see Table 3). 
The wall thickness $\left(t_{1}\right)$ after stretching will be:

$$
t_{1}=g_{r}-g \text {, }
$$

where:

$g_{r}-$ depth of the groove (in this study $g_{r}=0.2 \mathrm{~mm}$ ),

$g$ - thickness of the membrane (in $\mathrm{mm}$ ).

Similarly to equation (5), the wall thickness $\left(t_{0}\right)$ before stretching is :

$$
t_{0}=\frac{t_{1}}{1-v \cdot \frac{\varepsilon_{p}}{100}}
$$

Taking into account (6) and the $v$ and $\varepsilon$ values given in Table 2 , the $t_{0}$ values were calculated from (7). The resulting $t_{0}$ values for different membrane thickness $(\mathrm{g})$ are listed in Table 4.

Table 4. The wall thickness $\left(t_{0}\right)$ and the ring height $\left(h_{0}\right)$ of the unstretched ring for different thicknesses $(\mathrm{g})$ of the membrane.

\begin{tabular}{|c|c|c|c|c|c|}
\hline \multirow{2}{*}{$\begin{array}{c}\text { membrane } \\
\text { material }\end{array}$} & \multirow{2}{\mathbf{g}}{} & \multicolumn{2}{|c|}{$\boldsymbol{t}_{\mathbf{0}} \mathbf{( m m )}$} & \multicolumn{2}{c|}{$\boldsymbol{h}_{\mathbf{0}}(\mathbf{m m})$} \\
\cline { 3 - 6 } & & PTFE & PDMS & PTFE & PDMS \\
\hline PTFE & 0.05 & 0.31 & 0.40 & 0.31 & 0.71 \\
\hline PTFE & 0.10 & 0.21 & 0.27 & 0.21 & 0.51 \\
\hline PDMS & 0.10 & 0.21 & 0.27 & 0.21 & 0.51 \\
\hline PDMS & 0.11 & 0.19 & 0.24 & 0.19 & 0.47 \\
\hline PDMS & 0.12 & 0.17 & 0.21 & 0.17 & 0.42 \\
\hline PDMS & 0.13 & 0.15 & 0.19 & 0.15 & 0.38 \\
\hline PDMS & 0.14 & 0.13 & 0.16 & 0.13 & 0.33 \\
\hline PDMS & 0.15 & 0.10 & 0.13 & 0.11 & 0.28 \\
\hline
\end{tabular}

Next, the companies producing thin-walled tubes of such small diameters were found: i.e. Adtech (www.adtech.co.uk), Bakai (www.well-tube.com), Nelco (www.nelcoproducts.com), and WITKO (www.witko.com.pl).

Finally, based on the strain and the groove height $w_{r}=0.4 \mathrm{~mm}$, the $\left(h_{0}\right)$ values were calculated (Table 4$)$.

\section{Testing and results}

Before experimental testing, a mounting plate was made to facilitate the assembly of the chamber, membrane and ring, which are very small elements. The plate model was created using Autodesk Inventor Professional 2015. After the simulation of fitting the plate with the chamber (function collision analysis), the plate model was sent to the I.J. Paliga company. The plate was manufactured with the same method as the chamber (see Section 2.2).

The PDMS membrane (www.spiggle-theis.com) with thickness of $0.15 \mathrm{~mm}$, the rectangular cross-section rings cut off from the PTFE and PDMS tubes (www.witko.com.pl) and the printed chamber were used for testing (Fig. 5). Dimensions of the PTFE and PDMS rings were : $I D_{0}=3.03$ and $1.5 \mathrm{~mm}, t_{0}=0.2$ and $0.4 \mathrm{~mm}$, $h_{0} \approx 0.11$ and $0.28 \mathrm{~mm}$, respectively.

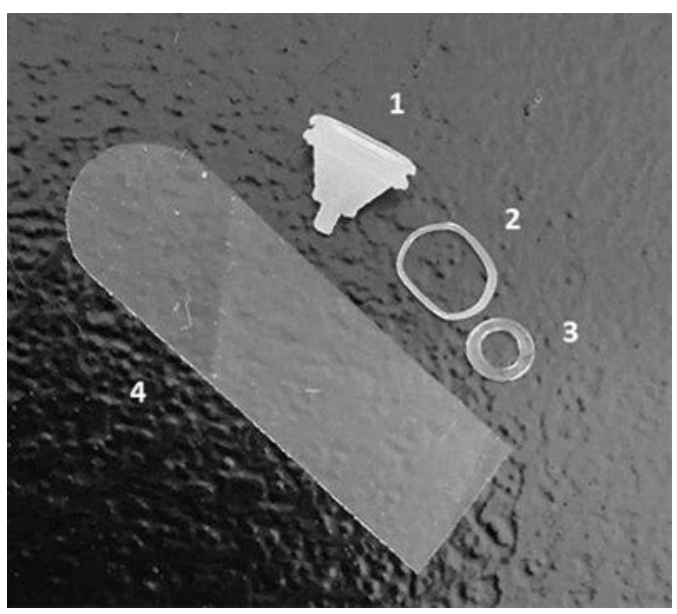

Fig. 5. Elements prepared for testing. 1 - chamber, 2 - PTFE ring, 3 - PDMS ring 4 - PDMS membrane.

At first, the rings were carefully and precisely cut off from the tubes. The length of the cut pieces was $h_{0}$. Subsequently, the chamber was placed onto the mounting plate and the membrane was placed on the upper surface of the chamber. Then the ring was manually stretched and inserted into the groove of the chamber using precision tweezers. Finally, an extra portion of the membrane was cut out. Fig. 6 shows the final result of the assembly procedure.

The stage consisting in stretching the PTFE ring in the elastic strain spectrum $(0-10 \%$, see Table 2$)$ was extremely difficult. It was easy to enter into the flow range of the polymer (necking region), which ended with a rupture, even after the reduction in tensile strength.

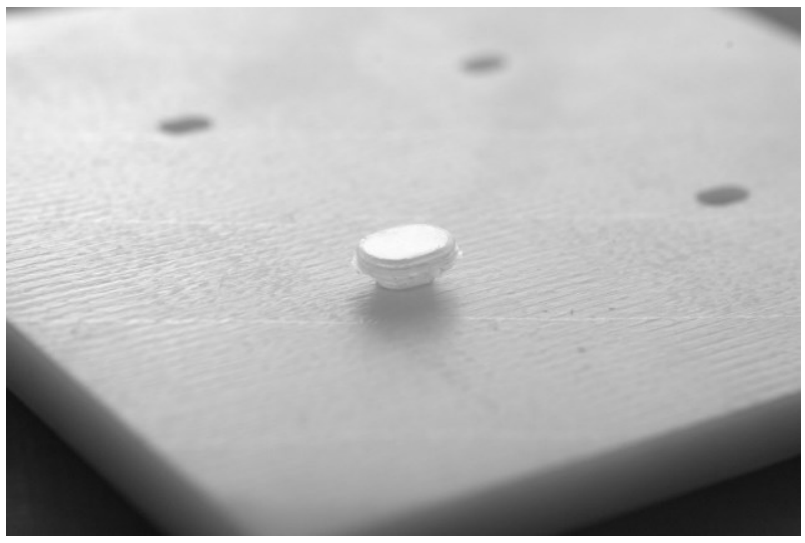

Fig. 6. Chamber with new fastening of the membrane located in the mounting plate.

In the case of a PDMS ring, significantly exceeding the $50 \%$ range of elastic strain, an attempt of stretching the ring was made. PDMS is a highly resilient biomaterial with properties similar to silicone rubber. The Young's modulus (E) of the PDMS is much lower than the one of the PTFE (see Table 2). Therefore, the more elastic PDMS proved a superior material for the designed fastening of the membrane. Unfortunately, purchase and testing of commercial PDMS micro o-rings (www.applerubber.com) was impossible due to their high price. 
Long-term and safe use of the ChSP requires a ring that would never slip out of the groove. To meet this requirement, the friction coefficient between the ring and the PDMS membrane should be as large as possible. Among the pairs PDMS (membrane) - PTFE (ring) and PDMS (membrane) - PDMS (ring), the latter is definitely more favourable.

In summary, the new fastening of the membrane was successfully tested with both the PTFE and the PDMS ring, but the PDMS ring would prove a significantly better choice.

The described tests are preliminary, and were conducted to analyze possible ideas for an improved fastening, to check how it works during application in the chamber and to select the preferred ones. To fully verify the functionality of the presented solution, it will be used in a prototype designed for experimental research. This prototype will be implanted in a human temporal bone and its functioning will be assessed based on vibration measurements and observation of the stability of the membrane fixation.

\section{Conclusions}

This study presented modification of the ChSP design in order to improve the fastening of the PDMS membrane to the chamber. By drawing on the computational method we obtained the geometrical model and an additional element which composed a new membrane fastening. The dimensions of the prosthesis are adjusted to the dimensions of the middle ear. The additional element meets the material properties requirements and the dimensions fitting into the groove. Finally, the process of manufacturing the entire structure is relatively uncomplicated, which is important in the case of such a small element like a ChSP.

Our solution brings far-reaching benefits of its application in the prosthesis.

The improved fastening can ensure safe implantation and long-term use. The risk of loss of chamber tightness and fluid leak can be eliminated. Moreover, fastening the membrane with the ring will certainly enhance the stability of the entire ChSP after the vibrating plate is placed on the membrane. The ChSP with the improved fastening ensures reduced risk and helps to avoid some of the possible post-operative complications.
Further works on improving the ChSP are in progress and will be continued, as this prosthesis creates an opportunity for better postoperative hearing results in patients with stapes otosclerosis.

This work was partially supported by the Polish National Centre for Research and Development (Research Project No. 266457/NCBR/2015). No additional funding was received for this study.

\section{References}

1. F.H. Linthicum jr., Otolaryngol. Clin. North. Am. 26 (1993)

2. G. L. Davis, Am. J. Otolaryngol. 8 (1987)

3. E. Olszewska, S. Chodynicki, B. Łazarczyk, Otolaryngol. Pol. 56 (2001)

4. C.W. Cummings, Otolaryngology - Head and Neck Surgery (St Louis, Mosby, 1998)

5. T. Gierek, L. Klimczak-Gołąb, Otolaryngol. Pol. 6 (2007)

6. J. J. Shea, Ann. Otol. Rhinol. Laryngol. 67 (1958)

7. www.kurzmed.com/products/otologie/stapedioplasty

8. R. Tange, W. Grolman, W. Dreschler, Otol. Neurol. 25 (2004)

9. W. Grolman, R. Tange, Otol. Neurol. 4 (2005)

10. I. Wegner, J. Verhagen, I. Stegeman, R. Vincent, W. Grolman, Laryngoscope, 1 (2016)

11. W. Gambin, M. Kwacz, M. Mrówka, Komorowa protezka ucha środkowego (Patent PL 271562 B1, 2014)

12. M. Kwacz, P. Marek, P. Borkowski, W. Gambin, Hear Res. 310 (2014)

13. M. Kwacz, M. Sołyga, M. Mrówka, K. Kamieniecki, PloS one. 12 (2017)

14. Y. Kawano, Y. Wang, R. A. Palmer, S. R. Aubuchon, Polímeros, 12 (2002)

15. O. Akogwu, D. Kwabi, S. Midturi, M. Eleruja, B. Babatope, W. O. Soboyejo, Mater. Sci. and Eng: B. 17 (2010)

16. P. Smith, R. W. Zappe, Elsevier 21 (2004)

17. I. D. Johnston, D. K. McCluskey, C. K. L.Tan, M. C.Tracey, J. Micromech. and Microeng. 24 (2014) 